\title{
DESAFIOS E AVANÇOS EDUCACIONAIS EM TEMPOS DA COVID-19
}

\section{EDUCAÇÃO EM TEMPOS DE PANDEMIA: DESAFIOS, REFLEXÕES, APRENDIZAGENS E PERSPECTIVAS}

Education in times of Pandemic: challenges, reflections, learning and perspectives

\author{
Jussara Santos Pimenta (iD) https://orcid.org/0000-0002-5283-2509 \\ Universidade Federal de Rondônia (UNIR) \\ e-mail - jussara.pimenta@unir.br
}

Priscila Brenha Abreu dos Santos (iD https://orcid.org/0000-0002-6701-623X

Universidade Federal de Rondônia (UNIR)

e-mail - pri.brenha@gmail.com

\author{
Bruna Renata de Brito Dantas (id) https://orcid.org/0000-0002-6179-1905 0000 \\ Universidade Federal de Rondônia (UNIR) \\ e-mail - bruna.renata3@gmail.com \\ Cristiane Carvalho Souza Bessa (iD https://orcid.org/0000 \\ Universidade Federal de Rondônia (UNIR) \\ e-mail - cristianecsbessa@gmail.com
}

\section{Resumo}

O presente estudo, elaborado metodologicamente a partir de pesquisa bibliográfica e documental, discute as mudanças ocorridas no cenário educacional, provocadas pela difusão da doença do Coronavírus e de como está sendo possível pensar os rumos da educação frente à crise, como uma exigência que se impõe aos educadores, aos educandos, aos pais, à escola. Também tece considerações e questionamentos sobre as adequações que foram sugeridas e realizadas no país e os desafios advindos das mesmas sobre o fazer docente e, consequentemente, sobre como esse aprender por via remota contribuiu para transformar o cotidiano dos professores, dos educandos e suas famílias. Como resultado, salientamos que o processo de aquisição de conhecimento por parte dos professores sobre as tecnologias da informação e da comunicação deve ser um processo permanente e não esporádico apenas para resolver as adversidades da pandemia.

Palavras-chave: Educação. Pandemia. Ensino Remoto. Ensino Aprendizagem. 


\begin{abstract}
This study, methodologically built on bibliographical and document search, discusses the changes that have occurred in the educational scenario caused by the spread of Corona Vírus Disease - COVID 19 and analyzes the direction that education is taking as a requirement imposed on educators, students, parents and school in the face of crisis. It also examines and questions the adaptations that have been suggested and carried out in Brazil, the challenges in teaching that have arisen from them, and, consequently, makes considerations on how this remote learning has contributed to transforming the daily lives of teachers, students and their families. As a result, we emphasize that the process of acquiring knowledge by teachers on information and communication technologies must be a permanent and not sporadic just to solve the adversities of the pandemic.
\end{abstract}

Keywords: Pandemic. Remote Teaching. Teaching and Learning.

\title{
Introdução
}

Era un libro muy viejo. El abuelo de Margie contó una vez que, cuando él era pequeño, su abuelo le había contado que hubo una época en que los cuentos siempre estaban impresos en papel.

Isaac Asimov (1951).

No dia 31 de dezembro de 2019, a China anunciou a gravidade do problema que estava enfrentando, chamando a atenção de todo o planeta para considerarem a urgência de desenvolverem ações eficientes como forma de combater a propagação da Covid-19. Com isto, devido a rapidez do contágio, no dia 30 de janeiro de 2020, a OMS - Organização Mundial da Saúde - decretou emergência de saúde pública de cunho internacional. Em 11 de março de 2020, a COVID-19 foi caracterizada como uma "pandemia", ou seja, já tinha atingido todo o hemisfério global.

Diante dos fatos, fez-se e faz-se necessário pensar os rumos da educação frente à crise, como uma exigência que se impõe aos educadores, aos educandos, aos pais, à escola. : Impossibilitados de continuarem com a presença física em sala de aula, os educadores se viram numa realidade que se impôs de se pensar novos caminhos para o desenvolvimento do seu fazer docente. Como afirmam Dussel, Ferrante e Pulfer (2020, p. 12), tudo levar a crer e querer comprovar que apenas o "que se mantiene en pie y crece es el avance científico-tecnológico" e os rumos da educação parecem só depender desses avanços tecnológicos e da desenvoltura dos professores em utilizá-los. A “digitalización de lo cotidiano" é uma certeza e é 
como se dela dependesse a sobrevivência de tudo e de todos: dos estudantes, dos professores, da escola, enfim, da educação. Os autores nos convocam a pensar nas seguintes questões:

\begin{abstract}
En nuestro espacio de actuación inmediato, la educación, aparecen algunos interrogantes específicos. ¿Qué productividad, qué aprendizajes, qué legados arroja la experiencia en modo remoto a la que se han visto obligadas escuelas y familias para darle continuidad a la tarea de educar? ¿Cómo pensar la educación, las nuevas relaciones y vínculos con lo social que se están tejiendo en este contexto de emergencia? ¿Cómo tematizar y problematizar las realidades de las escuelas por venir? (DUSSEL; FERRANTE; PULFER, 2020, p. 12).
\end{abstract}

Com o objetivo de refletir sobre algumas dessas questões, o presente estudo, elaborado metodologicamente a partir de pesquisa bibliográfica e documental, traz à discussão as mudanças ocorridas no cenário educacional, provocadas pela difusão do vírus da COVID -19, bem como as adequações que foram sugeridas e realizadas na Educação no país. O Governo Federal, juntamente com os representantes de cada Estado e Município e os demais poderes que formam a administração pública do país, tomou medidas emergenciais para combater o avanço da epidemia. Dentre essas ações efetuadas, está o isolamento/distanciamento social - como intervenção principal para se evitar a propagação da doença. De acordo com Lajolo (2020, s/p):

A pandemia que estamos enfrentando deixará marcas e impactará o futuro. Ainda não sabemos em que medida vai provocar mudanças nem quais serão suas consequências na ciência, na economia e na sociedade. Instituições, pesquisadores e profissionais de diversas áreas da medicina, da economia, das ciências sociais, da engenharia e de outras áreas debruçam-se sobre a questão. O que talvez permita acreditar que a ciência e as instituições de ensino e pesquisa, a partir de tudo o que estamos vivendo, possam - cada vez mais - estabelecer relações efetivas e reconhecidas com a sociedade.

À Escola, com suas dinâmicas estritamente entrelaçadas nas diferentes atividades de interação e como instância subordinada ao Ministério da Educação, foi demandado que aderisse ao estado de calamidade pública e, num primeiro momento, suspenderam as aulas presenciais, que ocorreu a partir do sancionamento da Lei no 13.979, de 6 de fevereiro de 2020, que dispôs "[...] sobre as medidas para enfrentamento da emergência de saúde pública de importância internacional decorrente do corona vírus responsável pelo surto de 2019 ". Em $1^{\circ}$ de abril do mesmo ano, foi assinada a Medida Provisória $n^{\circ} 934$ que, diante da inevitabilidade da situação, estabeleceu convocou escola e toda a comunidade 
escolar a repensar, replanejar suas práticas pedagógicas, para que o aluno não fosse penalizado pela situação atual, e isso se fez a partir do entendimento de que só seria possível por meio das aulas remotas. Sabemos que os estudantes, têm seus direitos assegurados pela Constituição Federal (1988) e pela Lei de Diretrizes e Bases da Educação Nacional (Lei n 9.394/1996). Esta última estabelece 200 dias letivos e a carga horária de 800 horas como forma de garantir o acesso aos conhecimentos historicamente construídos. Sendo assim, tanto a escola quanto o professor são alvos dessa nova demanda, ou seja, a de realizar mudanças, a de se adequarem a esta nova realidade incorporando as tecnologias de informação e comunicação na sua prática docente como recurso didático.

Com toda essa problemática a ser resolvida, o professor tem a seu favor, os conhecimentos prévios que estes alunos possuem, adquiridos de suas vivências extraescolares, e do tempo histórico no qual estão inseridos. Segundo Veen e Vrakking (2009), esta geração é chamada de "digital", "ciber" e da "rede", devido às características e comportamento, formados e impressos pela sociedade da informação e comunicação. Entretanto, tanto a Escola, quanto professores e alunos enfrentam desafios, que nas entrelinhas são dificuldades geradas pelos insumos, ou seja, a Escola não tem o aporte/suporte adequado para subsidiar o professor em materiais e acesso à internet. Ele, em contrapartida, precisa financiar com recursos próprios seu trabalho, ou seja, a necessidade de uma boa internet, de um computador capaz de propiciar acesso às ferramentas digitais mais sofisticadas para reproduzir multimídias, fica sob a exclusiva responsabilidade dos professores e das professoras, sem contar o espaço das casas, lugares de convívio familiar que se tornaram espaços de trabalho e de estudos dos filhos e familiares. Caso os estudantes tenham acesso virtual, o professor consegue realizar suas atividades, caso não haja essa disponibilidade, o professor precisará realizar um replanejamento para atender as peculiaridades de seus alunos.

Diante disso, constatamos que a Pandemia trouxe à tona as deficiências existentes nos setores primordiais do país, sobretudo nos setores da saúde e da educação. As escolas não estão aparelhadas para promover uma educação remota de qualidade. Nem os professores estão preparados para tal transformação e os estudantes estão na dependência do que os pais podem proporcionar e sabemos que a maioria, são filhos de trabalhadores que contam com recursos limitados para a sua sobrevivência. Como equalizar tantas dificuldades? 


\section{Entre contextos e exclusões}

-¿De la escuela? ¿Qué se puede escribir sobre la escuela? Odio la escuela.

Margie siempre había odiado la escuela, pero ahora más que nunca.

Isaac Asimov (1951).

Antes de se instalar o caos devido à pandemia, o estado das coisas já estava abalado no Brasil, especificamente no setor educacional. Segundo Santos (2020), a pandemia estremeceu o que já estava estremecido. O predomínio de políticas neoliberais na atualidade tem imposto ao país, uma paulatina e rigorosa diminuição da intervenção do Estado como agente de suprimento e investimento nos principais setores, revertendo toda dinâmica para os grandes investidores de mercado, enriquecendo uma minoria e colocando a maioria da população em estado de sobrevivência. De acordo com Boaventura (2020, p. 24):

[...] a versão actualmente vigente - o neoliberalismo combinado com o domínio do capital financeiro - está social e politicamente desacreditada em face da tragédia a que conduziu a sociedade global e cujas consequências são mais evidentes do que nunca neste momento de crise humanitária global.

Entretanto é com o que contamos nesse momento. Como retrato desta realidade imposta aos cidadãos, temos políticas públicas para a área da educação que deveriam estar voltadas para assegurar qualidade, equidade, acesso e permanência desse alunado na escola, que foram esvaziadas e as que permanecem, recebem cada dia menos verbas para assegurar a sua continuidade. Temos, por exemplo, a questão do FUNDEB - Fundo de Manutenção e Desenvolvimento da Educação Básica. A PEC15/2015, que trata no Novo FUNDEB, que financia a educação de Estados e Municípios (creches, pré-escolas e escolas de Ensino Fundamental e Médio, em suas diferentes modalidades) e inclusive o pagamento dos professores e o custeio de formação continuada. Esse financiamento tem sido alvo de disputas acaloradas e tem mobilizado educadores e parte da opinião pública. O Fundo terá o seu prazo vencido a partir de 31 de dezembro de 2020 e as discussões esbarravam no percentual de investimento financeiro que deveria ser feito pela União. Finalmente, em 25 de agosto de 2020 ocorreu a aprovação da PEC 26/2020, no Senado Federal do Fundeb com CAQ (Custo Aluno-Qualidade). 
Se havia um pressentimento entre educadores e o receio de que o FUNDEB fosse esvaziado, o que acabou não acontecendo, também observamos que outras medidas tomadas estão obstaculizando o bom desempenho da educação pública, gratuita e de qualidade. Ela vem sendo impactada por outras medidas, como por exemplo a extinção da SECADI - Secretaria de Educação Continuada, Alfabetização, Diversidade e Inclusão, que elaborava propostas para a inclusão e que contribuíam para o acesso, a garantia, a permanência e a continuidade das minorias na escola. A SECADI foi extinta por meio do Decreto $n^{\circ} 9.465$, de 2 de janeiro de 2019. A Secretaria previa o desenvolvimento dos sistemas de ensino, voltado à valorização das diferenças e da diversidade sociocultural, à promoção da educação inclusiva, dos direitos humanos e da sustentabilidade socioambiental. Sua atuação previa ações e contribuições nos campos da Educação de Jovens e Adultos, Educação Especial na perspectiva inclusiva, Educação Ambiental e em Direitos Humanos, Educação do Campo, Indígena e Quilombola e Educação para as Relações Étnico-Raciais. Como medida de contenção de gastos e/ou divergências políticas e ideológicas dos novos gestores da pasta da educação, se extinguiu esta Secretaria, por meio do Decreto $n^{\circ}$ 9.465, de 2 de janeiro de 2019, que planejava ações para a inclusão destes sujeitos no âmbito escolar. Com a extinção da Secretaria, violam-se os direitos estabelecidos na Constituição Federal, no Art. 205, que determina que:

\footnotetext{
A educação, direito de todos e dever do Estado e da família, será promovida e incentivada com a colaboração da sociedade, visando ao pleno desenvolvimento da pessoa, seu preparo para o exercício da cidadania e sua qualificação para o trabalho.
}

Outros programas também foram extintos e/ou não contam mais com verbas para a permanência e êxito de seus objetivos e atividades. Podemos citar, por exemplo, o Programa Nacional Biblioteca da Escola - PNBE, que foi extinto em 2017 depois de não ter recebido aportes financeiros que garantiam a sua continuidade desde 2015 (CORDEIRO, 2018, p. 1492). Entre os "anos de 2000 e 2014 foram quase 230 milhões de exemplares" e investidos "R $\$ 891$ milhões em compras", ou seja, "em média, R\$ 68,5 milhões por ano na renovação dos acervos para estudantes de todos os anos do Ensino Básico (Infantil, Fundamental e Médio), como afirma Moreira (2017, s/p). 
Com essa política econômica e entendendo a Educação como gasto e não como investimento, entendemos que esta reflexão se faz necessária, tendo em vista, que a Escola e sua comunidade têm sido penalizadas por essas ações, que em tempos de pandemia deveria estar sendo acolhida por políticas públicas que contribuíssem para abrandar a exclusão e garantir a permanência e o sucesso na escolarização. Foram extintas e não se tem previsão de revitalização dessas políticas públicas. Além disso, não há no sistema educacional público verba disponível e suficiente para equipar todas as escolas com laboratórios de informática, sala de robótica, bibliotecas, recursos e ferramentas atuais que possibilitem aos estudantes aprendizagens significativas. Que resta às crianças de baixa renda, senão odiar a escola que não compreendem? Que pouco poderá fazer por elas? O que está previsto é apenas as aulas remotas. Mas com que propósitos e com que qualidade estão sendo realizadas?

\section{Desafios em tempos de pandemia}

Supongo que cuando terminas el libro lo tiras. Nuestra pantalla de televisión habrá mostrado un millón de libros y sirve para muchos más.

Isaac Asimov (1951).

No Brasil, para criar-se a ideia de garantia do direito da criança em tempos de pandemia, o sistema educacional teve que se organizar às pressas para atender a comunidade escolar, com vistas a efetivação de um sistema pedagógico virtual, sendo necessário a adaptação do corpo docente ao novo método emergencial de ensino. As aulas precisaram ser adaptadas, ministradas e assistidas dentro das casas das famílias de maneira remota, o que tem ocasionado uma série de desafios, tanto para os docentes quanto para pais e estudantes.

Para que seja adotada uma modalidade de ensino remoto na Educação Básica, mesmo nas situações previstas em lei, um conjunto de aspectos precisa ser levado em consideração, de maneira a proporcionar a oferta de uma educação igualitária e não excludente, direito constitucional de todos os alunos, sem exceção: o que demanda da escola um planejamento do processo ensino e aprendizagem diferenciado, reorganização curricular distinta e adequada, sobretudo, por exigir uma nova dinâmica para o trabalho pedagógico dos docentes. Para Boaventura (2020, p. 22): 
As crises graves e agudas, cuja letalidade é muito significativa e muito rápida, mobilizam os media e os poderes políticos, e levam a que sejam tomadas medidas que, no melhor dos casos, resolvem as consequências da crise, mas não afectam as suas causas. Pelo contrário, as crises graves, mas de progressão lenta tendem a passar despercebidas mesmo quando a sua letalidade é exponencialmente maior. A pandemia do coronavírus é o exemplo mais recente do primeiro tipo de crise.

Sendo assim, com os impactos na educação, o cenário educativo deve ser discutido pelas políticas públicas urgentemente. É importante ressaltar que as práticas pedagógicas no que tange ao ensino e à aprendizagem exigem a diferenciação dos termos que adentraram as rotinas escolares nesse período de isolamento. Os abismos sociais que ficaram evidentes com o ensino a distância e nesse contexto a implementação de aulas remotas, faz o leigo compreender que tudo é integrante de um único bloco que constitui aprendizagem. O que faz necessário explicar a diferença entre educação a distância e o que são aulas remotas.

Para esclarecer o conceito de Ensino a Distância - EaD, o Artigo 80 da Lei de Diretrizes e Bases da Educação Nacional (9.394/96) nos diz, em seu Inciso $4^{\circ}$, que essa educação tem como pressuposto desenvolver-se a distância assíncrona, ou seja, que não ocorre ao mesmo tempo. Embora haja legislação que prevê o atendimento excepcional e a implementação das aulas remotas nesse período de pandemia, situação excepcional vivenciada no mundo inteiro, podemos observar que na literatura educacional não existe normatização sobre o "ensino remoto", uma vez que, diante do contexto de pandemia da Covid-19, é uma experiência nova. Essa modalidade remota utiliza plataformas para adaptação da mediação didática e pedagógica de forma síncrona e assíncrona, que significa que acontece ao mesmo tempo. Sua aplicação foi possível por intermédio da portaria emitida pelo Ministério da Educação n 343 de 17 de março de 2020, que diz o seguinte:

Dispõe sobre a substituição das aulas presenciais por aulas em meios digitais enquanto durar a situação de pandemia do Novo Coronavírus COVID-19.

O MINISTRO DE ESTADO DA EDUCAÇÃO, no uso da atribuição que Ihe confere 0 art. 87, parágrafo único, incisos I e II, da Constituição, e considerando $o$ art. $9^{\circ}$, incisos II e VII, da Lei $n^{\circ} 9.394$, de 20 de dezembro de 1996, e o art. $2^{\circ}$ do Decreto $n^{\circ} 9.235$, de 15 de dezembro de 2017, resolve:

Art. $1^{\circ}$ Autorizar, em caráter excepcional, a substituição das disciplinas presenciais, em andamento, por aulas que utilizem meios e tecnologias de informação e comunicação, nos limites estabelecidos pela legislação em 
vigor, por instituição de educação superior integrante do sistema federal de ensino, de que trata o art. $2^{\circ}$ do Decreto $n^{\circ} 9.235$, de 15 de dezembro de 2017.

Santos e Pellanda (2020) ressaltam que o Estado brasileiro, por meio dos seus gestores, precisará considerar a garantia do direito à educação de todas as pessoas que estão matriculadas nas escolas do país. Dessa forma, com a paralisação do calendário letivo, a solução apontada para resolução do problema sobre essa paralisação, buscou-se adequar as aulas para o formato de aulas remotas, para não causar maiores problemas a respeito da negação do direito à educação. Nesse tocante, o ensino online, ou seja, por meio das tecnologias digitais, tem sido a única alternativa pensada para dar seguimento à educação formal.

Muitos são os desafios para implementar o ensino remoto na Educação Básica do país. De acordo com Lévy (2014, p. 390) "o meio digital é um meio de comunicação mundial, multimídia, interativo e ubíquo aberto a uma multidão crescente de comunidade de usuários.". Porém, é preciso lembrar que os usuários contam com realidades diversas, famílias e alunos que apresentam dificuldades na utilização de plataformas online de ensino, seja por falta de conhecimentos ou o acesso à internet, professores que necessitam de formação técnica para orientar os processos pedagógicos de aprendizagem em ambientes virtuais, por meio de vídeo aulas, transmissões ao vivo, entre outros mecanismos de ensino. São desafios que se ampliam no contexto da rede pública da zona urbana e rural. Conforme Valadares (2020):

\begin{abstract}
Uma pesquisa divulgada em 2019 aponta que 58\% dos domicílios no Brasil não têm acesso a computadores e 33\% não dispõem de internet. Entre as classes mais baixas, o acesso é ainda mais restrito. A pesquisa foi feita pelo Comitê Gestor da Internet no Brasil (CGI.br), entre agosto e dezembro de 2018. Os dados apontam que, nas áreas rurais, nem mesmo as escolas têm acesso à rede mundial de computadores: $43 \%$ delas afirmavam que o problema é a falta de infraestrutura para o sinal chegar aos locais mais remotos.
\end{abstract}

Nesse contexto, as dificuldades para implementação das aulas remotas pode ser constatada a partir do enfrentamento das instituições públicas diante das dificuldades encontradas em tornar as aulas acessíveis a todos os alunos, o que torna ainda mais marcante o processo de desigualdade social em meio a educação brasileira, de maneira que nem todos os professores e estudantes têm acesso à 
internet, pois em alguns lugares esse acesso não é possível, sendo limitado para alguns, principalmente para aqueles de baixa renda.

Observa-se que o Estado tem buscado maquiar essa realidade, pois segundo Tostes e Filho (2020), tem se apresentado um ponto de partida verdadeiramente igualitário para todos a partir da concepção de que todos tivessem ou tenham efetivamente uma boa educação. A desigualdade social entre os estudantes tem sido evidenciada ao se constatar que muitos podem ter acesso à internet, computador e aparelhos de telefonia celular ou notebooks, mas uma parcela considerável da população não dispõe de acesso às essas tecnologias, acarretando dificuldades ou impossibilidade no acompanhamento das aulas.

É importante analisar que além dos desafios intensificados pela emergência da situação, onde não houve tempo para planejamento, preparação de aulas ou materiais diferenciados que o professor enfrenta em relação à execução das suas atividades pedagógicas virtuais, há que se considerar as diferentes situações familiares, pois como seria possível as crianças acompanharem as aulas mediadas pela tecnologia, se muitas das famílias estão passando por dificuldades financeiras, entre outras questões? Nesse sentido Boaventura (2020, p. 19) destaca: "Se as escolas fecham, acaba a merenda escolar que garantia a sobrevivência das crianças." O problema é grave, porque muitas famílias dependem da merenda escolar, pois sem a alimentação é fato que as crianças não conseguem sobreviver, sequer aprender.

Diante desse atual cenário, os desafios enfrentados pelos professores surgem, consequentemente, a partir da ausência de habilidades em aliar o uso da tecnologia às práticas pedagógicas, visto que há profissionais que trabalham há muitos anos em sala de aula fazendo uso do modo convencional de ensino. Segundo Ribeiro, Castro e Regattieri (2007) para a integração das tecnologias ao processo educativo há a necessidade de os professores obterem conhecimentos teóricos e práticos sobre elas, principalmente competência tecnológica para saber selecioná-las e utilizá-las adequadamente, pois, sem os conhecimentos oferecidos pela internet como pode o professor orientar seus alunos para a busca de informações sobre determinado assunto da disciplina?

Se este profissional não conhece um software educativo, como indicar aos alunos a sua utilização? Estamos diante de uma situação que precisa ser repensada pelas políticas públicas e pelas instituições de ensino, com vistas em investimentos 
necessários para o desempenho pedagógico do hoje, para a contemporaneidade e para o amanhã, uma vez que a atuação pedagógica precisa voltar-se também para desenvolvimento do aluno e também para a formação do professor para tal desafio, em relação ao uso da tecnologia.

Nesse cenário os docentes acabam pressionados a conseguir fazer tudo o que é demandado, na maioria das vezes em curto prazo, vindo a diminuir mais ainda a qualidade do ensino oferecido. Sobretudo houve um aumento da jornada de trabalho em que o professor não consegue estabelecer uma rotina de trabalho adequadamente, principalmente em relação a quando está trabalhando ou resolvendo suas atividades pessoais. Há uma certa dificuldade na realização das atividades pedagógicas, já que há professores e gestores que não tiveram nenhuma formação voltada para o ensino por meio das tecnologias da informação e da comunicação.

É importante salientar que a preocupação tem sido apenas com a transmissão exagerada de conteúdos imposta por um sistema emergencial de ensino, que se aproxima muito de uma educação bancária, conforme Paulo Freire (1987, p. 33): "Desta maneira, a educação se torna um ato de depositar, em que os educandos são os depositários e o educador o depositante." Há que se refletir sobre essa prática pedagógica, na qual a preocupação excessiva volta-se para a transmissão de acúmulo de conteúdos para os educandos, na maioria das vezes fora da realidade e da necessidade prática do estudante. Sendo assim, o método pedagógico que está sendo tentado no ensino remoto, ainda que disponha de aporte tecnológico, traz semelhanças com o ensino tradicional, pois muitas das atividades acabam por manter o educando passivo no processo de ensino e aprendizagem.

Como supracitado, a inserção das tecnologias e das plataformas digitais na prática docente é uma necessidade, dada as exigências desse tempo histórico em que vivemos, no qual o centro está na qualidade da aprendizagem que se consegue oferecer aos educandos. Entretanto, esta ação colide com as dificuldades impostas pelo próprio sistema escolar. A escola enfrenta como necessidade imediata a formação permanente dos professores para as tecnologias digitais, sendo que há falta de treinamento para o uso de plataformas digitais na educação. Quanto à formação dos profissionais do ensino, também é conveniente observar que os cursos de formação de professores disponibilizam precariamente a aquisição do 
conhecimento em tecnologias digitais em seus currículos. Isso significa que há necessidade de disciplinas que promovam maior interação com os mecanismos e ferramentas tecnológicas, o que causa uma lacuna na formação inicial, acarretando problemas posteriormente no campo e desempenho profissional. Sobre a questão, Valente (2000) salienta que:

[...] muitos educadores ainda não sabem o que fazer com os recursos que a informática oferece. E, nesse sentido, a chave do problema é a questão da formação, da preparação de educadores para saberem como utilizar esta ferramenta como parte das atividades que realizam na escola. (VALENTE, 2000, p. 6).

Levando em consideração esse contexto, os desafios enfrentados pelos professores, tem suas explicações na ausência dessas habilidades, que estão sendo impostas pela situação atual/social. Esse grupo profissional procura superar suas dificuldades para cumprir com as demandas que lhe são conferidas, muitas vezes realizando uma formação adicional que é custeada com os seus próprios recursos. Sendo assim, a deficiência não é só dos profissionais da educação, mas de todo o aparelho responsável em organizar, fomentar e dirigir a sistema educacional brasileiro, que não vislumbrou uma necessária transformação, mais que urgente, tendo que fazer alinhavos, remendos para dar conta de garantir o direito dos estudantes.

\section{Novas aprendizagens diante de um novo cenário educacional}

Lo que más odiaba Margie era la ranura por donde debía insertar las tareas y las pruebas.

Siempre tenía que redactarlas en un código que le hicieron aprender a los seis años, y el maestro automático calculaba la calificación en un santiamén.

Isaac Asimov (1951).

Diante dos inúmeros desafios apresentados na dinâmica que constitui os procedimentos de aprendizagem em sala de aula, é possível entrever o que o aluno já sabe, a partir do que ele produz e pensar no que fazer para que se oportunize mais aprendizado. Assim, as questões que envolvem as situações de ensino e aprendizagem permitem que o professor olhe para o que o aluno produziu, perceba o que já sabe e identifique que tipo de informação é necessária para que seu conhecimento avance. Conforme Weisz (2009): 
[...] uma concepção que considera o processo de aprendizagem como resultado da ação do aprendiz contempla, nessa abordagem, que a função do professor é criar as condições para que o aluno possa exercer a sua ação de aprender, participando de situações que favoreçam isso. As ações, nesse caso, não implicam necessariamente atividade física aparente, mas atividade mental, exercício intelectual (WEISZ, 2009, p. 2223).

Ainda em conformidade com Weisz (2009, p. 24), "[...] cada concepção de aprendizagem produz sua própria linha de investigações [...]". Na concepção construtivista, o conhecimento é visto como produto da ação e reflexão do aprendiz. Esse ser aprendente é visto como alguém que tem determinado conhecimento e que, a partir de novas informações que fazem sentido para ele, realiza um esforço para assimilá-las. Do mesmo modo, quando o aluno é colocado diante de situações problemas, depara-se com a necessidade de superação. Por essa razão, é imprescindível o conhecimento prévio que o aprendiz tem sobre qualquer conteúdo. Nesse entendimento, Weisz (2009, p. 24) afirma que "[...] o conhecimento novo aparece como resultado de um processo de ampliação, diversificação e aprofundamento do conhecimento anterior que ele já detém" [...].

A educação brasileira tem sido marcada por profundas alterações em todos os seus pilares educacionais e mesmo em meio a significativas transformações, no que tange aos processos formativos e educativos, não era possível prever mudanças tão abruptas em um curto espaço de tempo. Ressignificações da maneira convencional do ensino deram espaço para ferramentas tecnológicas, exigindo do professor uma nova concepção e adequação para o fazer pedagógico.

Foi neste cenário onde muitas famílias em ação conjunta com a escola tiveram que se adaptar, tendo como um dos protagonistas nesse processo, a figura do professor. Este profissional está tendo que se reinventar, adequar-se à uma estrutura de ensino com a inclusão de aulas remotas como possibilidade de continuidade do ano letivo numa eventual validação de carga horária e em muitos casos, também como justificativa para manutenção de salários e mensalidades escolares.

Os sistemas de ensino, mesmo de maneira emergencial como o caso que a pandemia requer, precisaram considerar as diferenças entre a linguagem adotada no ensino presencial e a mediação que ocorre a partir dos recursos tecnológicos. Uma mudança abrupta na interatividade entre os sujeitos envolvidos no processo de ensino e aprendizagem, o que resultou em novos mecanismos de estímulo 
cognitivos e também revelou disparidades educacionais a que nossa sociedade está inserida, como a dificuldade ao acesso à internet e seus recursos. Sobre a questão Mercado (1999, p. 27) afirma:

As novas tecnologias criam novas chances de reformular as relações entre alunos e professores e de rever a relação da escola com o meio social, ao diversificar os espaços de construção do conhecimento, ao revolucionar os processos e metodologias de aprendizagem, permitindo à escola um novo diálogo com os indivíduos e com o mundo.

Nesse sentido, enfatiza-se que diante das tecnologias exige-se das escolas e secretarias a necessidade de agregar ao perfil do profissional de ensino a formação e capacitação acerca da inserção destas tecnologias. Diante disso, escolas das redes privadas, municipais e estaduais precisam investir em cursos de formação continuada de apoio para o manuseio de ferramentas de ensino na elaboração de formulários eletrônicos, plataformas de ensino para envio de vídeo aulas e atividades e até mesmo de integração com aulas online.

Não obstante, não basta apenas a oferta de formação, que contém participação massiva do professorado. Esse profissional precisa de fato estar habilitado e confortavelmente preparado para manusear essas diferentes ferramentas tecnológicas sem eventual prejuízo educacional tanto para quem ensina como para quem aprende. "O domínio das técnicas acontece por necessidades e exigências do pedagógico e as novas possibilidades técnicas criam novas aberturas para o pedagógico, constituindo uma verdadeira espiral ascendente na sua complexidade técnica e pedagógica." (PRADO; VALENTE, 2000, p. 22).

Em meio aos tempos atuais grande parte dos professores brasileiros da Educação Básica não está preparado para utilizar as ferramentas tecnológicas no processo de ensino e aprendizagem, inclusive para ensinar por meio de transmissões on-line. Nesse sentindo, faz-se necessário repensar o processo de formação inicial e continuada do professor. Surge a necessidade de adequação às atividades pedagógicas, como por exemplo o uso de recursos tecnológicos. Tornase imprescindível hoje e futuramente, no processo de formação permanente do professor. Como afirma Imbernón (2009, p. 18): "É preciso analisar o que funciona, o que devemos abandonar, o que temos de desaprender, o que é preciso construir de novo ou reconstruir sobre o velho." 
Nesse sentido, é papel da escola equalizar as oportunidades de aprendizagens de seus estudantes, distanciando-se de uma pedagogia compensatória, ou seja, um conjunto de medidas políticas e pedagógicas visando compensar as deficiências físicas, afetivas, intelectuais e escolares dos estudantes das classes cultural, social e econômica, a fim de que elas se preparem para o mercado de trabalho e tenham oportunidades plurais de ascensão e atuação social como cidadãos autônomos, críticos e participativos. A equalização das oportunidades de aprendizagens, em nosso entendimento, traduz a educação como instrumento permanente de cidadania e de inserção social.

\section{Considerações Finais}

Estaba pensando en las viejas escuelas que había cuando el abuelo del abuelo era un chiquillo. Asistían todos los chicos del vecindario, se reían y gritaban en el patio, se sentaban juntos en el aula, regresaban a casa juntos al final del día. Aprendían las mismas cosas, así que podían ayudarse a hacer los deberes y hablar de ellos. Y los maestros eran personas...

Isaac Asimov (1951).

No texto, trazemos como epígrafes alguns trechos do conto "Cuánto se divertían", de Isaac Asimov (1951), imaginado e escrito numa realidade do início da segunda metade do século $X X$, quando se dispunha como base tecnológica para informação e comunicação e se considerava a contribuição do rádio e da televisão. No conto, Asimov apresenta um diálogo entre duas crianças, Margie e Tommy, num dia qualquer do mês de maio do ano de 2157. Tommy se surpreende por haver "encontrado un libro de verdad!" Os livros tinham páginas amarelas e era "divertidísimo ver que las palabras se quedaban quietas en vez de desplazarse por la pantalla. Y, cuando volvías a la página anterior, contenía las mismas palabras que cuando la leías por primera vez." (ASIMOV, 1951, p. 1).

Os garotos se surpreendem também que as crianças e jovens não eram educadas por professores "normais", mas por homens. "¿Un hombre? ¿Cómo puede un hombre ser maestro?" (ASIMOV, p. 2). E que esses homens explicavam coisas às crianças, Ihes davam tarefas, faziam perguntas. "No es posible. Un hombre no puede saber tanto como un maestro." (ASIMOV, p. 2). E a maior surpresa: os professores não vinham à casa dos alunos, mas os alunos acorriam à um "edifício especial" denominado escola. Tudo muito diferente da experiência que 
tinham com professores automáticos, que explicavam lições desde que se sintonizasse a "pantalla" previamente preparadas e ajustadas à idade da criança a ser ensinada. Para aceder às lições bastava ir até o dormitório e "el maestro automático se hallaba encendido ya y esperando. Siempre se encendía a la misma hora todos los días, excepto sábados y domingos [...]”. (ASIMOV, 1951, p. 3). Diante da sua realidade e experiências com as "pantallas iluminadas", processo individual de aprendizado, a menina pensava que aquelas crianças do passado deveriam ser felizes naquela "[...] escuela en los viejos tiempos. Pensaba en cuánto se divertían" [...]. (ASIMOV, 1951, p. 4). Aquelas crianças aprendiam com outras crianças, liam livros divertidos, se deslocavam de casa para o tal "edifício especial" chamado escola e tudo isso, seguramente parecia bem mais divertido que as aulas solitárias no seu dormitório.

De acordo com Lévy (1998, p. 4) estão surgindo "[...] novas maneiras de pensar e de conviver estão sendo elaboradas no mundo das Telecomunicações e da informática [...]". Dessa forma, também são tecidas novas "relações entre os homens, o trabalho, a própria inteligência depende, na verdade, da metamorfose incessante de dispositivos informacionais de todos os tipos" (LÉVY, 1998, p. 4). Se os homens são metamorfoseados também são transformadas a escrita, a leitura, a visão, a audição, a criação e a aprendizagem, todas elas "capturadas por uma informática cada vez mais avançada" (LÉVY, 1998, p. 4).

Com os rumos da educação diante da pandemia da Covid-19, temos situações de similaridade com o descrito no conto de Isaac Asimov (1951). Talvez possamos pensar na possibilidade de tais experiências virem a ser o cotidiano de jovens e crianças se estenderem mais que o previsto. Por outro lado, também podemos pensar se nesse momento de pandemia dependemos tanto das tecnologias da informação e da comunicação, como será a educação a partir de agora, depois dessa experiência? Como será a escola a partir do que estamos vivenciando nesses dias de pandemia, de pós-pandemia e de futuras pandemias? Como iremos enfrentar? Teremos "pantallas iluminadas" em todos os lares e um professor automático a dar lições, bastando que se ajustem alguns parâmetros para iniciarem as aulas?

Com base no entendimento a partir da empiria sobre o assunto, o presente artigo teve como objetivo trazer reflexões e perspectivas a partir dos desafios e aprendizagens a que os sistemas educacionais, sejam eles federais, estaduais ou 
municipais, estão tendo que enfrentar para solucionar os desafios advindos da pandemia da Covid-19. Vale salientar que, por mais que exista uma inclinação para a aplicação de boas práticas atreladas ao uso das tecnologias digitais, fica claro também que essas ações são resultado de um processo que deve ser contínuo e não apenas esporádico, por conta de uma situação adversa como a que vivemos, a pandemia, ou tratado de forma pontual, como a mercantilização do setor educacional trata a questão.

Sobre os desafios atrelados aos trabalhos vinculados ao uso e disponibilidade das tecnologias digitais em tempos de pandemia, alguns aspectos são ressaltados como: a ausência de local apropriado para as aulas remotas; a falta de apoio familiar ou de familiares com conhecimento suficiente para o acompanhamento dos estudos; a falta de interesse dos alunos; a necessidade de conhecer a realidade sociocultural e psicológica de cada aluno; conhecer a dinâmica socioafetiva das famílias, bem como o meio em que este encontra-se inserido. Todas essas questões impactam os resultados do ensino, afinal lidamos com pessoas e não com "pantallas iluminadas". Quanto aos estudantes, eles têm a experiência das aulas presenciais, onde há troca de impressões e socialização em todos os momentos das aulas com o professor e com os colegas, onde há recreio, brincadeiras, merenda.

De parte dos professores, fica evidenciado que os desafios encontrados consistem em ter que trabalhar com atividades diferenciadas e equiparar a turma quando esta tem acesso às mídias digitais. Verificamos, também, que os professores estão se desdobrando para dar conta da nova demanda imposta pelas aulas remotas e acabam por chamar para si tal responsabilidade, como se esta não fosse parte integrante do sistema educacional, mas atribuições individuais de cada professor, de cada professora. A formação presencial é indispensável, pois lidamos não apenas com conteúdos nas escolas, tratamos da educação de seres humanos, onde há subjetividade envolvida: afeto, valores, ética, estética, e por esta razão transferir a responsabilidade do espaço de uma sala de aula para tela de um computador, tablet ou aparelho celular, relativiza todo o mecanismo educacional. Embora a escola apresente em seus pilares aparente fragilidade, ainda é nela que se encontra a verdadeira integração responsável pelos desdobramentos do ensino e da aprendizagem. 


\section{Referências}

ASIMOV, Isaac. Cuantó se divertían. Disponível em: https://ciudadseva.com/texto/cuantose-divertian/. Acesso em: 18 ago. 2020.

BRASIL. Lei de Diretrizes e Bases Lei n 9.394/96, de 20 de dezembro de 1996. Disponível em: http://www.planalto.gov.br/ccivil_03/Leis/L9394.htm. Acesso em: 24 jun. 2020.

BRASIL. Medida Provisória n 343, de 17 de março de 2020. Aprova substituição das aulas presenciais por tecnologias digitais, Brasília, DF. Disponível em: http://pesquisa.in.gov.br/imprensa/jsp/visualiza/index.jsp?data=18/03/2020\&jornal= 515\&pagina=39\&totalArquivos=125. Acesso em: 24 jun. 2020.

BRASIL. Ministério da Educação. Fundo Nacional de Desenvolvimento da Educação. Brasília, DF. Disponível em: https://www.fnde.gov.br/financiamento/fundeb. Acesso em: 25 jun. 2020.

BRASIL. Presidência da República. Lei n 13.979, de 6 de fevereiro de 2020.

Disponível em: http://www.planalto.gov.br/ccivil 03/ ato2019-

2022/2020/lei/L13979compilado.htm. Acesso em: 06 out. 2020.

BRASIL. Presidência da República. Medida Provisória no 934, de $1^{\circ}$ de abril de 2020. Disponível em: https://www.in.gov.br/en/web/dou/-/medida-provisoria-n-934de-1-de-abril-de-2020-250710591. Acesso em: 06 out. 2020.

BRASIL. Presidência da República. Decreto nº 9.465, de 2 de janeiro de 2019.

Disponível em: https://www.in.gov.br/materia/-

lasset publisher/Kujrw0TZC2Mb/content/id/57633286. Acesso em 06 out. 2020.

CORDEIRO, Maisa Barbosa da Silva. Políticas Públicas de Fomento à Leitura no Brasil: uma análise (1930-2014). Educ. Real., Porto Alegre, v. 43, n. 4, p. 14771497, out. 2018. Disponível em http://www.scielo.br/scielo.php?script=sci_arttext\&pid=S2175-

$62362018000401477 \&$ Ing=pt\&nrm=iso. Acessos em 06 out. 2020. Epub 08-Out2018. https://doi.org/10.1590/2175-623675138.

DUSSEL, Inés; FERRANTE, Patricia; PULFER, Darío. Presentación. In: DUSSEL, Inés; FERRANTE, Patricia; PULFER, Darío. (Org.). Pensar la educación en tiempos de pandemia: entre la emergencia, el compromiso y la espera. Ciudad Autónoma de Buenos Aires: UNIPE: Editorial Universitaria, 2020. Libro digital, PDF - (Políticas educativas; 6).

FREIRE, Paulo. Pedagogia do Oprimido. 17ª . Ed. Rio de Janeiro, Paz e Terra, 1987.

IMBERNÓN, Francisco. Formação Permanente do Professorado: Novas Tendências /Francisco Imbernón; Tradução de Sandra Trabucco Valenzuela. São Paulo: Cortez, 2009. 
LAJOLO, Franco, Maria. Covid-19, ciência, público e políticas públicas. São Paulo: Jornal da USP, 2020. Disponível em: https://jornal.usp.br/artigos/covid-19ciencia-publico-e-politicaspublicas/. Acesso em: 22 ago. 2020.

LÉVY, Pierre. A esfera semântica. São Paulo: Annablume, 2014.

LÉVY, Pierre. As tecnologias da inteligência: o futuro do pensamento na era da informática. Rio de Janeiro: Editora 34, 1998.

MERCADO, Luis Paulo Leopoldo. Formação continuada de professores e novas tecnologias. Maceió: EDUFAL, 1999.

MOREIRA, Ardilhes. Governo federal está desde 2014 sem comprar livros de literatura para escolas públicas. O Globo, 29/09/2017. Disponível em: https://g1.globo.com/educacao/noticia/governo-federal-seguira-sem-entregarnovos-livros-de-literatura-para-bibliotecas-escolares-em-2018.ghtml. Acesso em: 19 ago. de 2020 .

RIBEIRO, Antônia. CASTRO, Jane Margareth de. REGATTIERI, Marilza Machado Gomes. Tecnologias na Sala de Aula: uma expectativa em escolas públicas do Ensino Médio. Brasília: UNESCO, MEC, 2007.

SANTOS, Boaventura de Souza. A Cruel Pedagogia do Vírus. EDIÇÕES ALMEDINA, S.A. Abril, 2020.

SANTOS, Catarina de Almeida; PELLANDA, Andressa. Guia COVID-19 Educação a Distância. Volume 3 EAD. São Paulo, 2020. Disponível em: https://media.campanha.org.br/acervo/documentos/COVID-19_Guia3EaD_FINAL.pdf. Acesso em: 21 jun. de 2020.

TOSTES, Anjuli; FILHO, Hugo Melo. Quarentena: reflexões sobre a pandemia e depois. ilustração de Carlo Giambarresi. - 1.ed. -Bauru: Canal 6, 2020. Recurso digital. - (Projeto Editorial Praxis).

VALADARES, Marcelo. Coronavírus faz educação a distância esbarrar no desafio do acesso à internet e da inexperiência dos alunos. Rio de Janeiro, G1, 23/03/2020. Disponível em: https://g1.globo.com/educacao/noticia/2020/03/23/coronavirus-faz-educacao-adistancia-esbarrar-no-desafio-do-acesso-a-internet-e-da-inexperiencia-dosalunos.ghtml. Acesso em: 22 jun.2020.

VALENTE, José Armando. (Org.). Formação de educadores para o uso da informática na escola. - Núcleo de Informática Aplicada à Educação - NIED Universidade Estadual de Campinas - Unicamp; São Paulo, 2000.

VEEN, Win. VRAKKING, Ben. Homo Zappiens: educando na era digital. Tradução: Vinícius Figueira - Porto Velho; Artmed, 2009.

WEISZ, Telma. O diálogo entre o ensino e a aprendizagem. 2.ed. São Paulo: Ática, 2009. 
Recebido: $27 / 08 / 2020$

Aprovado: 02/12/2020

Como citar: PIMENTA, J. S. et al. Educação em tempos de pandemia: desafios, reflexões, aprendizagens e perspectivas. Revista de Estudos e Pesquisas sobre Ensino Tecnológico (EDUCITEC), v. 6, Ed. Esp. Desafios e avanços educacionais em tempos da COVID-19, e141320, 2020.

Direito autoral: Este artigo está licenciado sob os termos da Licença Creative CommonsAtribuição 4.0 Internacional.

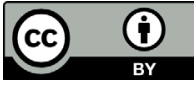

